\title{
Hypothesis
}

\section{The Y specific growth gene(s): how does it promote stature?}

\author{
Tsutomu Ogata, Nobutake Matsuo
}

\begin{abstract}
Although the presence of a $Y$ specific growth gene(s) ( $Y$ growth gene(s)) on $Y q$ has widely been accepted, it remains unknown how this gene promotes stature. In this report, we discuss the growth pattern in normal boys and girls and in patients with growth disorders informative for the $Y$ growth gene(s). The results suggest that the $Y$ growth gene(s) augments statural growth by controlling the sex steroid independent childhood growth pattern.

(f Med Genet 1997;34:323-325)
\end{abstract}

Keywords: Y specific growth gene(s); childhood growth.

We have proposed the presence of a Y specific growth gene(s) ( $Y$ growth gene(s)) that augments adult height by $8-10 \mathrm{~cm}$ independently of the effect of gonadal sex steroids. ${ }^{12}$ This hypothesis is primarily based on white adult height comparisons between patients with pure $\mathrm{XY}$ gonadal dysgenesis and those with pure $\mathrm{XX}$ gonadal dysgenesis $(172.0 \mathrm{~cm}$ (SD 7.0), $\mathrm{n}=24 v 164.3 \mathrm{~cm}(\mathrm{SD} 7.7), \mathrm{n}=22, \mathrm{p}<0.01)$, between patients with complete testicular feminisation syndrome and normal females (172.2 cm (SD 6.5), $\mathrm{n}=23 v 162.2 \mathrm{~cm}$ (SD 6.0 ), the British standard, $\mathrm{p}<0.01$ ), and between normal males and XX males (174.7 $\mathrm{cm}$ (SD 6.7), the British standard, $v 166.4 \mathrm{~cm}$ (SD 7.4), $\mathrm{n}=33, \mathrm{p}<0.01$ ), in whom the sex chromosome complement is different but the effect of bioactive gonadal sex steroids is similar. ${ }^{12}$ Furthermore, we have localised the $Y$ growth gene(s) to the proximal $\mathrm{Yq}$ region between DYS11 and DYS246, by genotypephenotype correlations in non-mosaic adult male patients with a partial Yq deletion. ${ }^{3}$ Here, we discuss how the $\mathrm{Y}$ growth gene(s) promotes statural growth.

The mean height (supine length during infancy and standing height thereafter) is in principle greater in boys than in girls, except for around the ages of 12 to 14 years when girls become taller than boys because of the earlier onset of the pubertal growth spurt. ${ }^{4}$ It is noteworthy that the statural difference between the sexes remains only $0.5-2.0 \mathrm{~cm}$ in childhood but increases to about $13 \mathrm{~cm}$ in adulthood. ${ }^{4}$ This may raise the possibility that the $\mathrm{Y}$ growth gene(s) augments stature in conjunction with gonadal sex steroids.

However, the sex difference in the height gain from childhood to adulthood is not inconsistent with the $\mathrm{Y}$ growth gene(s) acting in a sex steroid independent manner. The human growth pattern is divided into three additive and partially superimposed components (infancy, childhood, and puberty) on the basis of mathematical modelling of auxological data. ${ }^{5}$ Although the infantile growth component tails off by 3-4 years of age, the childhood growth component continues to mature height. Thus, the height gain from childhood to adulthood is the sum of the height increase caused by the extension of the sex steroid independent childhood growth and that added by the sex steroid dependent pubertal growth. According to the Swedish longitudinal growth study, mean childhood growth is expressed by the following second degree polynomial function: boys, $\mathrm{Y}=-0.18 \mathrm{X}^{2}+8.53 \mathrm{X}+71.9$ and girls, $\mathrm{Y}=-0.22 \mathrm{X}^{2}+8.93 \mathrm{X}+69.9$ ( $\mathrm{Y}$ : height in $\mathrm{cm}$; $\mathrm{X}$ : age in years). ${ }^{5}$ This sex difference in the childhood growth function produces only $2 \mathrm{~cm}$ of height difference at 10 years of age but yields $10 \mathrm{~cm}$ of height difference at 20 years of age. Thus, it is assumed that the $\mathrm{Y}$ growth gene(s) controls the sex steroid independent childhood growth pattern, leading to the adult height difference of $8-10 \mathrm{~cm}$. The remaining adult height difference between the sexes is explained by the notion that testicular sex steroids have the potential to increase the adult height by $3-5 \mathrm{~cm}$ whereas ovarian sex steroids have no major effect on the adult height. ${ }^{12}$

If the above assumption is correct, it is expected that the $\mathrm{Y}$ growth gene(s) leads to sex difference in height, which remains hidden in childhood but becomes obvious in adulthood, in disorders lacking a pubertal growth spurt. In this regard, growth data are available in achondroplasia in which sex steroids fail to cause an apparent growth spurt because of severely compromised bone capacity of linear growth. In this disease, the sex difference in the mean height remains only $0.5-1.0 \mathrm{~cm}$ in childhood, but becomes gradually clearer during puberty, amounting to about $7 \mathrm{~cm}$ in adulthood. ${ }^{6}$ This growth pattern is consistent

\footnotetext{
Received 15 July 1996 Revised version accepted fo publication 15 November 1996

Department of
Paediatrics, Keio

Medicine, 35

Shinjuku-ku, Tokyo

T Ogata

Correspondence to: Dorrespon Ogata
} 
Boys

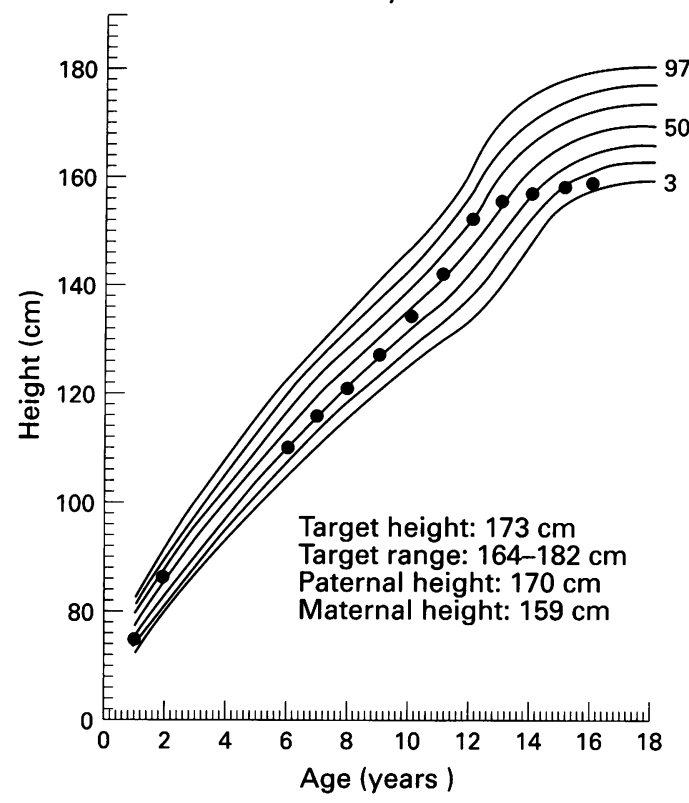

Girls

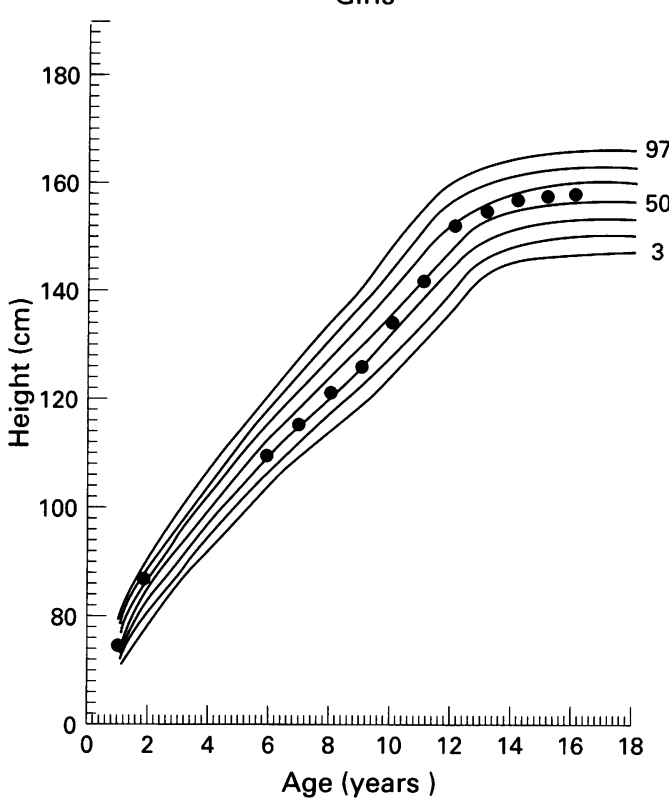

Figure 1 A clinical model for a possible mutation of the $Y$ growth gene(s). The height data of a 46,XY male patient with short stature of pubertal onset are plotted on the fapanese height standard for normal boys (left) and that for normal girls (right). The curves depict the 97th, 90th, 75th, 50th, 25th, 10th, and 3rd centile statural values. Target height (a child's final height as predicted from the parental height) and target range ( $95 \%$ confidence interval of target height) were obtained from the equations for fapanese boys. ${ }^{9}$ The height gain from childhood to adulthood is obviously small for boys but almost appropriate for girls. This growth pattern is plausibly explained by assuming a mutation of the Y growth gene(s) that controls the childhood growth pattern. The upward height shift during puberty, as indicated by the growth chart plotted on the female standard, is consistent with the patient having testes rather than ovaries. Similar growth patterns have also been observed in seven further 46,XY male patients.

with the notion that the $\mathrm{Y}$ growth gene(s) promotes adult height by controlling childhood growth. Similar growth patterns have also been reported in Laron syndrome ${ }^{7}$ and in Down syndrome, ${ }^{8}$ although the growth data are insufficient to draw a definite conclusion.

It is also expected that a mutation of the $\mathrm{Y}$ growth gene(s) results in a male to female alteration of the childhood growth pattern and, therefore, causes growth deficiency that is hardly recognised in childhood but becomes discernible in adulthood. We have experienced eight $46, \mathrm{XY}$ male patients who exhibit such a unique growth pattern (fig 1). These patients may represent clinical models for a mutation of the Y growth gene(s), although the possibility remains purely speculative at present.

One may argue against the above hypothesis, because several male patients with Yq deletions have short stature which is already obvious in childhood. ${ }^{10}$ Such short stature is not explicable by assuming loss of the $\mathrm{Y}$ growth gene(s) that is expected to cause a male to female alteration of the childhood growth pattern. However, the Yq deletions are associated with chromosome imbalance (quantitative alteration of euchromatic or non-inactivated region $^{2}{ }^{11}$ ), and it has been suggested that chromosome imbalance could disturb developmental homeostasis or impair cell proliferation, resulting in global non-specific developmental defects including growth failure. ${ }^{12}{ }^{13}$ In fact, karyotype-phenotype correlations in sex chromosome aberrations are consistent with chromosome imbalance being involved in the development of several features including growth failure. ${ }^{2311}$ Furthermore, it is possible that the $\mathrm{Yq}$ deletions are caused by cryptic unbalanced translocations involving the $\mathrm{X}$ chromosome or the autosomes, rather than by simple Yq deletions. Indeed, cryptic Xq;Yq translocations have been reported in several retarded patients with Yq- chromosomes. ${ }^{14}$ Such unbalanced translocations would result in gross chromosome imbalance and perturbation of multiple non-Y linked genes, exerting a deleterious effect on statural growth. Thus, short stature in boys with Yq deletions would not provide compelling evidence against the hypothesis that the $\mathrm{Y}$ growth gene(s) is responsible for the sex difference in the childhood growth pattern.

In summary, we propose that the $\mathrm{Y}$ growth gene(s) promotes statural growth by controlling the childhood growth pattern. Furthermore, the $\mathrm{Y}$ growth gene(s) might also be involved in fetal growth, since sex difference in fetal body size in eutherian mammals is partly ascribed to the growth advantage brought about by a Y linked gene(s) other than Sry. ${ }^{15}$ The hypothesis will be tested when the $\mathrm{Y}$ growth gene(s) has been cloned.

1 Ogata T, Matsuo N. Comparison of adult height between patients with XX and XY gonadal dysgenesis: support for $Y$ specific growth gene(s). F Med Genet 1992;29:539-41.

2 Ogata T, Matsuo N. Sex chromosome aberrations and stature: deduction of the principal factors involved in the determination of adult height. Hum Genet 1993;91:551-62

3 Ogata T, Tomita K, Hida A, Matsuo N, Nakahori Y, Nakagome Y. Chromosomal localisation of a $Y$ specific growth gene(s). f Med Genet 1995;32:572-5.

4 Tanner JM. Normal growth and techniques of growth assessment. Clin Endocrinol Metab 1986;15:411-51.

5 Karlberg J. On the modelling of human growth. Stat Med 1987;6:185-92.

6 Horton WA, Rotter JI, Rimoin DL. Standard growth curves for achondroplasia. $\mathcal{f}$ Pediatr 1978;93:435-8.

7 Laron Z, Lilos P, Klinger B. Growth curves for Laron Laron Z, Lilos P, Klinger B. Growth curve
syndrome. Arch Dis Child 1993;68:768-70.

8 Cronk C, Crocker AC, Pueschel SM, et al. Growth charts for children with Down syndrome: 1 month to 18 years of age. Pediatrics 1988;81:102-10. 
9 Ogata T, Matsuo N, Tamai S, Osano M, Tango T. Target height and target range for the Japanese. fpn f Paediatr

10 Davies RM. Localisation of male determining factors in man: a thorough review of structural anomalies of the $Y$ chromosome. F Med Genet 1981;18:161-95.

11 Ogata T, Matsuo N. Turner syndrome and female sex chromosome aberrations: deduction of the principal factors involved in the development of clinical features. Hum Genet 1995;95:607-29.

12 Epstein CJ. The consequences of chromosome imbalance: principles, mechanisms, and models. Cambridge: Cambridge University Press, 1986
13 Gilbert EF, Opitz JM. Developmental and other pathologic changes in syndromes caused by chromosome abnormalities. Perspect Pediatr Pathol 1982;7:1-63.

14 Lahn BT, Ma N, Breg WR, Stratton R, Surti U, Page DC. $\mathrm{Xq}-\mathrm{Yq}$ interchange resulting in supernormal $\mathrm{X}$-linked gene expression in severely retarded males with 46 , XYq- karyotype. Nat Genet 1994;8:243-9.

15 Burgoyne PS, Thornhill AR, Boudrean $K$, Darling AM, Bishop CE, Evans EP. The genetic basis of XX-XY differences present before gonadal sex differentiation in the mouse. Philos Trans R Soc Lond B 1995;350:253-61. 